\title{
TERRITORIO ESTRATÉGICO DE SUAPE: IMPACTOS DE UN MODELO DE DESARROLLO Y OCUPACIÓN TERRITORIAL
}

\author{
Fernando Clímaco Santiago Maciel \\ Serviço de Apoio às Micro e Pequenas Empresas do Estado de Pernambuco - SEBRAE PE (Brasil) \\ Contacto: fernandoc@pe.sebrae.com.br
}

Fecha de recepción: 11/05/2015

Fecha de aceptación: 01/10/2015

\section{Resumen}

El complejo industrial puerto de Suape, en el municipio de Ipojuca, Pernambuco, recibió en los últimos diez años, alrededor de $\$ 20$ millones de dólares de inversiones públicas y privadas. El optimismo de las autoridades y las inversiones multimillonarias, sin embargo no ha sido suficiente para promover la calidad de vida en su propio entorno. Los municipios de Territorio Estratégico Suape siguen enfrentándose a graves problemas sociales, bajos niveles de educación y el desarrollo humano, agravada por los impactos ambientales causados por las grandes inversiones industriales, como la deforestación y amenaza el medio ambiente marino, y las amenazas de vulnerabilidad social de diversos grupos y familias. Este estudio trata de comprender los factores que están involucrados con esta realidad que hace que tanta riqueza siendo incapaz de generar bienestar en los municipios circundantes y al mismo tiempo ser capaz de potencialmente empeorar la calidad de vida en el territorio como ya se ha demostrado en algunos estudios y, principalmente la percepción de los que viven allí.

Palabras clave: Complejo de Suape. El desarrollo local. Desarrollo sustentable. Competitividad empresarial.

TERRITORY OF STRATEGIC SUAPE: IMPACTS OF A DEVELOPMENT MODEL AND TERRITORIAL OCCUPATION

\section{Summary}

The Industrial Port Complex of Suape (CIPS) located in Ipojuca, Pernambuco, has received over the past decade, about $\$ 20$ billion of public and private investments. The authorities of optimism and billionaires investments, however, has not been sufficient to promote quality of life in their own surroundings. Municipalities Strategic Territory of Suape (TES) remain facing serious social problems, aggravated by environmental impacts and threats of socially vulnerable groups and families. This study sought to understand the factors that cause so much wealth is unable to generate welfare in surrounding municipalities and at the same time potentially be able to worsen the quality of life in the territory as shown by some studies and especially the perception of those who live there.

Keywords: Suape Complex. Local development. Sustainable development. Business competitiveness.

\section{TERRITOIRE STRATÉGIQUE DE SUAPE: IMPACTS D'UN MODÈLE DE DÉVELOPPEMENT ET L'OCCUPATION} TERRITORIALE

\footnotetext{
Résumé

"Le Complexe Industriel Portuaire de Suape, localisé dans la commune d'Ipojuca, dans l'état de Pernambuco, a reçu ces dix dernières années, environ 20 milliards de dollars d'investissements publics et privés. L'optimisme des autorités et des investissements millionnaires n'a toutefois pas été suffisant pour promouvoir la qualité de vie de son propre environnement. Les communes du Territoire Stratégique de
} 
Suape continuent d'affronter de graves problèmes sociaux ; le taux de scolarité et de développement humain est très bas, aggravés par les impacts environnementaux provoqués par les grands investissements industriels, comme la déforestation qui menace le milieu marin, ainsi que les vulnérabilités sociales de divers groupes et familles. Ce travail a cherché à comprendre les facteurs qui sont responsables de cette réalité qui permet qu'une telle richesse soit incapable de gérer le bien-être des communes aux alentours et en même temps, être potentiellement capable d'aggraver la qualité de vie des territoires, comme cela a déjà été démontré dans certaines études, et principalement la perception de ceux qui y vivent".

Mots-clés: Complexe de Suape. Le développement local. Développement durable. La compétitivité des entreprises.

\section{INTRODUCCIÓN}

Hace dez años el complejo Suape recibió inversión de \$20 mil millones y cerca de 150 empresas instaladas, atraídos por las características positivas del puerto, sino también por un agresivo programa de beneficios incentivos y beneficio fiscales. Los CIPS se ha convertido en el centro de producción de los ocho municipios que conforman los TES: Cabo de Santo Agostinho, Ipojuca, Jaboatão dos Guararapes, Escalera, Moreno, Sirinhaém y Ribeirao Formoso río, totalizando 1,2 millones de habitantes. Sólo los dos primeros son considerados territorios de influencia directa. Los otros municipios vecinos - son considerados influencia indirecta.

EI TES se ha convertido en un ejemplo emblemático de un territorio con un crecimiento del PIB a partir del modelo típicamente de "'top-down"" y no conseguió evitar la precariedad de la vida en las ciudades y la amenaza de la degradación ambiental del medio ambiente, contribuyendo a generar una profunda brecha entre los resultados económicos obtenidos por los propietarios de los medios de producción y la calidad de vida de las personas que viven alrededor del complejo.

Dados los niveles de inversión pública y privada recibida por la región en los últimos años, se ha convertido en relevante para la búsqueda, investigar qué factores al bajo nivel de desarrollo territorial de los municipios que rodean el complejo industrial de Suape y porqué el crecimiento económico no se ha traducido en el desarrollo para todos.

La encuesta realizada se apoya teoricamente en el enfoque sistémico y complejo do desarrollo. Las tendencias de la globalización del sistema económico y de la crisis del medio ambiente, ha llevado a una reinterpretación de las bases de desarrollo. Este nuevo contexto replantea los aspectos clave de desarrollo territorial a fin de que la estructuración de una política de desarrollo territorial en cuenta todo su concepto multidimensional, superando el punto de vista exclusivamente económico. Una propuesta que revela toda la complejidad que implica el "desarrollo", reconociéndolo como un concepto "profundamente axiológico, multidimensional, cualitativa en su esencia e intangible por consecuência" (Boisier, 2001).

La nueva propuesta surge desde el fracaso del modelo tradicional de las políticas de desarrollo de arriba-abajo (top-down), cuyos objetivos principales son para atraer grandes inversiones a través de subsidios, incentivos a la ubicación y la inversión pública en infraestructura. En la mayoría de los casos, la transferencia de recursos (tecnología de capital, mano de obra calificada) entre zonas desarrolladas y menos desarrolladas redujo el potencial de desarrollo en las regiones desfavorecidas que tienden a inhibir la capacidad 
empresarial local, la creación de nuevas empresas, así como comprometer la consolidación de las empresas existentes, ya que los salarios y las "facilidades" ofrecidas por las grandes corporaciones se vuelven atractivos para los trabajadores locales.

La política de desarrollo endógeno o de abajo a arriba, a su vez, actúa como catalizador de los mecanismos de desarrollo a través de iniciativas locales: facilita el desarrollo empresarial y de la creación de redes de empresas, alienta la difusión de la innovación y el conocimiento, mejora la diversidad urbana, y alienta el desarrollo del tejido institucional. Uno de sus principales objetivos debe ser promover la mejora continua de los recursos empresariales, haciéndolas más competitivas, y allá allende estimular la capacidad emprendedora de ciertos grupos sociales clave, como los jóvenes y las mujeres (BARQUERO, 2006).

\section{INVESTIGACIÓN}

Dada la complejidad de la escena y lo que se propone analizar, una cuestión clave fue definir los límites de la observación. Al principio, el plan era mirar el Territorio Suape y a partir de la identificación de posibles factores que afectan en la contradicción entre el crecimiento y el desarrollo, bajo la teoría. Este camino, sin embargo, podría dar lugar a una multiplicidad de factores y razones tan diversas que probablemente genera viabilidad en su sistematización. Para establecer límites que nos ofrecen un análisis más productiva, se decidió a la inversa, la elección de algunos de los elementos clave de la teoría que contribuyen a un modelo de desarrollo sostenible, tales como lentes o potenciales, de ver la realidad. Cada tema, a priori definido como importante generador de desarrollo sostenible, se constituyó en el delimitador de observación. De este modo fue posible identificar y evaluar cualitativamente, ¿qué factores podrían ser y cómo podrían interferir con la realidad concreta del territorio Suape y, al mismo tiempo, son las repercusiones en la teoría.

Por lo tanto, el objetivo general de los estudios fue investigar a la luz de las teorías y estudios que apoyan la propuesta de un nuevo modelo de desarrollo territorial sostenible, qué factores han influido para un territorio que ha sido escenario de inversión de orden incomún, mantega sus municipios experimentando un profundo déficit social, en muchos casos con gravedad a causa de las actividades relacionadas con el crecimiento econômico, y algunos objetivos específicos adicionales que verifiquen la posible evidencia de la degradación del medio ambiente; el surgimiento de los grupos vulnerables en función de la ocupación del territorio y de la posible relación entre el modelo basado en la atracción de inversión extranjera y la formación de una cultura empresarial local.

Definido estas perspectivas se construyó el esquema metodológico que trató de combinar varias posibilidades de construcción de conocimientos alrededor del objeto: a) análisis de las estadísticas oficiales; b) pesquisa bibliográfica; c) recuperación histórica de noticia; y d) investigación documental. 


\section{SUAPE, LA JOYA DE LA CORONA}

Hace diez años, desde que anunció la construcción de una refinería de petróleo en la Provincia de Pernambuco, que tuvo inicio un proceso de entusiamo respecto a las perspectivas de crecimiento de la economía, y el impacto que esto traería a la vida de todos los pernambucanos. En el primer evento oficial en noviembre de 2010, la firma de un memorando de entendimiento entre el gobernador Jarbas Vasconcelos ${ }^{1}$, presidente de Petrobras, José Sergio Gabrielli de Azevedo $^{2}$ y el presidente del Complejo Industrial Portuario de Suape, Matheus Guimaraes Antunes, los números anunciandos eran astronómicos y animadores para el estado de Pernambuco. La prensa anunciaba 240.000 puestos de trabajo entre directos, indirectos y los que fueron generados por el efecto renta en cuatro anõs de aplicación y el pago de 970 millones de dólares en impuestos estatales y locales anualmente, tras el comienzo de su funcionamiento. (BAHIA NEGÓCIOS, 2010)

"Va a ser una revolución", quizás la palabra más usada por el afán que acometía los sectores públicos del gobierno en Pernambuco y el oportunismo de los grandes inversores interesados en las cifras que implican la operación y sobre todo el establecimiento de una refinería de petróleo en cualquier parte del mundo. Esta vez, sin embargo, a pesar de toda las possibilidades que tenía Petrobras para construir su 14a refinería en Brasil después de más de veinte años de la última obra, la elección recayó en el estado de Pernambuco y de esta opción, la estructura y características el Puerto de Suape, en Ipojuca fueron decisivos.

La Refinería Abreu e Lima, que llegó a ser disputada por nueve estados brasileños, abriría una nueva era para Pernambuco, aunque integre un proceso de industrialización tardía del Noreste, y sería la principla inversión, ancla para el surgimiento de una cadena totalmente nueva la producción relacionada con las actividades petroleras.

En los años siguientes, especialmente durante los dos mandatos del gobernador Eduardo Henrique Aciolly Campos, Pernambuco acompañó por la prensa el anuncio de cientos de nuevas empresas que aportarían en Pernambuco. Las nuevas empresas, especialmente las industrias procedentes de Sureste de Brasil y algunos otros países se anunciaron en firma formal de cartas de intención, eventos que buscaban alimentar la confianza de la población proponiendo la redención económica del Estado y al mismo tiempo promoviendo la proyección política de grupos en el poder.

Casi al mismo tiempo la Refinería Abreu e Lima, otras dos grandes empresas forman el trío de las inversiones estructurales y redentores del nuevo Pernambuco: el Astillero Atlántico Sur, el más grande del hemisferio sur, con el tamaño y la capacidad de producción que equivale a astilleros asiáticos; y PetroquímicaSuape, un producto químico industrial textil complejo conjunto de tres grandes unidades industriales: la primera produce el ácido tereftálico purificado, conocido como PTA, la segunda es responsable por

\footnotetext{
${ }^{1}$ Gobernador de Pernambuco de 1 de enero de 1999 hasta 31 de marzo de 2006 (WIKIPÉDIA, 2015)

2 33.o Presidente de la Petrobras, de 22 de julio de 2005 hasta 13 de febrero de 2012 (WIKIPÉDIA, 2015) 55o Governador de la Provincia de Pernambuco de 1 de enero de 2007 hasta 4 de abril de 2014 (FOLHA DE SÃO PAULO, 2008)
} 
la fabricación de polímeros y filamentos de poliéster, y la tercera, es responsable por la producción de resina de embalaje PET (PETROQUÍMICA SUAPE, 2013).

Tabla 1 - proyectado inversiones para el Complejo Puerto de Suape

\begin{tabular}{l|c|c}
\hline EMPRENDIMENTOS & INVERSÓN (US\$ Bi) & EMPLEOS DIRECTOS \\
\hline Refinaria Abreu e Lima & 13,30 & 1.500 \\
Petroquímica Suape & 2,75 & 1.800 \\
Mossi \& Guisolf & 0,39 & 450 \\
Cia. Siderúrgica Suape & 0,83 & 800
\end{tabular}

Fuente: (Governo de Pernambuco, 2010)

En conjunto, las grandes empresas se estimaron en aproximadamente \$17.4 mil millones en inversión extranjera, junto con una generación de más de 11.000 puestos de trabajo directos. En 2011, el Gobierno de Pernambuco publica, a través del Decreto 37.169 / 201124 de septiembre, el nuevo Plan Director de Suape. Un documento de 14 volúmenes que servirían como "brújula" (SUAPE, 2011) para su desarrollo.

A pesar de hacer referencias a las cuestiones sociales y ambientales, el nuevo Plan Director de Suape es claramente un plan de expansión con cifras impresionantes. Uno de los aspectos más destacados del proyecto es la distinción de un área de 634 hectáreas para la creación de un cluster naval. Las pretenciones eran aumentar su tamaño por casi diez veces con el fin de recibir los nuevos estalleros que se estaban anunciados para el puerto. "Nuestra ambición es ser el centro naval más grande del país", dijo el secretario de Desarrollo Económico de Pernambuco Fernando Bezerra Coelho. (PE_DESENVOLVIMENTO, 2009)

En marzo de 2010, Pernambuco ya celebraba el anuncio del quinto y sexto astillero que se instalarían en Suape consolidando el centro naval de Pernambuco. Se trataba de los astilleros portugueses MPG Shipyards y del grupo coreano STX Europe, que juntos se invertirían casi \$ 500 millones que generando más de 5.000 empleos directos en Suape y cerca de 20.000 puestos de trabajo indirectos. Coelho dijo durante la firma del memorando de entendimiento que "la tarde del 26 de marzo será recordado como un momento histórico en Pernambuco." En esta fecha, Pernambuco llegaría a la impresionante cifra de seis astilleros anunciados que añadían a 3.0 mil millones de dólares en inversiones, más de 20 mil empleos directos y entre 60 e 80 mil indirectos. (PE_DESENVOLVIMENTO, 2010).

Los números de la llamada "cluster naval" ya eran impresionantes en 2010, pero no eran definitivos y al cabo de cinco años (2007-2012), nueve astilleros habían firmado memorandos de entendimiento con el Gobierno de Pernambuco. Juntos sumarían más de seis mil millones de reales, casi veinticinco mil empleos directos. Sin embargo, sólo dos se asentaron de manera efectiva en Suape. (tabla 2)

El proyecto para un nuevo agrupamiento naval es un ejemplo emblemático de las intenciones y las proyecciones hechas para Suape, siempre en la frontera entre el optimismo y casi megalomanía. Y esta expansión efectivamente ocurrió, asociada a un agresivo programa de incentivo fiscal, PRODEPE que entre 2007 y 2014, atrajo a 806 
proyectos industriales en todo el estado con inversiones de $\mathrm{R} \$ 19,9$ mil millones de reales y la creación de 79, 6000 empleos directos y una política abierta de difusión y comercialización, que empezó a "vender" Suape y Pernambuco en grandes eventos nacionales e internacionales, como el mejor destino de Brasil para nuevas inversiones (PERNAMBUCO, 2014).

Tabla 2 - Astillero anunciados para SUAPE

\begin{tabular}{lccl}
\hline EMPRENDIMENTO & $\begin{array}{c}\text { INVERSIÓN } \\
\text { (R\$ Millón) }\end{array}$ & EMPLEO & \multicolumn{1}{c}{ STATUS ACTUAL } \\
\hline Astillero Atlântico Sul & 1.380 & 8.000 & Operando en Suape \\
Astillero PROMAR & 300 & 1500 & Operando en Suape \\
Astillero CMO & 900 & 7.000 & No confirmado \\
Astillero Schahin/Tomé & 300 & 1.700 & Se instaló en Rio de Janeiro \\
Astillero Alusa/Galvão & 800 & 2.500 & Se intaló en Rio de Janeiro \\
Astillero Galíctio & 880 & 1.000 & No confirmado \\
Astillero Mpg Shipyards & 280 & 1.200 & No confirmado \\
Astillero STX Europe & 700 & 4.000 & No confirmado \\
Astillero Navalmare & 200 & 1.000 & No confirmado \\
\hline
\end{tabular}

Fuente: PE DESENVOLVIMENTO

Hay dos citaciones estampadas en el sitio Complejo de Suape, atribuídas a Francisco Cunha, arquitecto y consultor en la consultoría estratégica TGI, y a la economista de Pernambuco Tania Bacelar, que ilustraron cómo se reflejaban estas inversiones en la confianza y el concepto de Pernambuco respecto a Suape: "Suape es la joya de la corona de Pernambuco. Una maravilla de la logística. Un ahorro de la gente de Pernambuco hicieron durante más de 30 años sin interrupción y en el lugar correcto."; y "Pernambuco hoy tiene una serie de ventajas competitivas para acoger un importante centro de empresas de la cadena del petróleo, el gas, en alta mar y de la construcción naval y la presencia de una refinería de petróleo y varios astuilleros de dar fe de este potencial." 3

A pesar de muchos de estos proyectos no se hayan confirmado, se ha consolidado muy competente en la mente de la sociedad Pernambuco, el concepto de "Nueva Pernambuco," rica y próspera, competitiva y capaz de asumir una posición de liderazgo económico y político en el país. Bajo el nuevo paradigma, en Pernambuco, aunque no hay pruebas de lo contrario, todos los proyectos de inversión se traducirá en éxito. Al igual que el mito de Midas, el nuevo Pernambuco convierte en oro todo lo que toca.

\footnotetext{
${ }^{3}$ http://www.suape.pe.gov.br/home/index.php
} 


\section{DIRECTRICES PARA LA OCUPACIÓN SOSTENIBLE}

Junto a todo este movimiento de desarrollo, comienzan a surgir en Pernambuco, la preocupación por la ocupación de Suape y sus alrededores. El ecosistema de Suape y los municipios de la región se ven fuertemente afectados por la concentración de la inversión.

Essa concentração de investimentos tanto representa uma boa perspectiva de desenvolvimento e crescimento, como traz, no seu bojo, o risco de impactos sociais e ambientais de alta monta, a exemplo de degradação ambiental e a migração intensa e irregular que acarreta o aumento da demanda por habitação, transporte, serviços sociais, além de infraestrutura e demais serviços, tanto para os usos residenciais quanto produtivos. (BRAGA y QUEIROZ, 2009 a)

Fueron estas preocupaciones, todavía preliminares, lo que lleva la Agencia CONDEPE / Fidem, órgano de planificación y pesquisas del Gobierno de Pernambuco, a establecer y coordinar en el año 2007 un grupo de trabajo para construir directrices y recomendaciones para una ocupación sostenible del territorio estratégico de Suape, teniendo como socios en este esfuerzo, así como otros órganos de la administración estatal, cinco municipios del área de Suape de influencia: Ipojuca y Cabo de Santo Agostinho, base del complejo y considerados de influencia directa y todavía Jaboatão Guararapes, Moreno y Escada, clasificados como municipios de influencia indirecta. (BRAGA y QUEIROZ, 2009 b)

El documento Directrices para Ocupación Sostenible para el Territorio Estratégico de Suape publicado en 2008, trae el resultado de estos estudios, y trae encuestas y recomendaciones basadas en tres áreas clave: 1) organización del territorio y vivienda, 2) Movilidad y 3) Saneamiento y medio ambiente. El documento debe seguir la guía para el proceso de ocupación del territorio Suape para los planificadores, inversores y responsables de las políticas, a fin de minimizar los impactos negativos de las grandes inversiones.

El territorio de Suape Estratégico estaba, pues extremadamente tensionado por un movimiento expansionista, de desarrollo centrado en el crecimiento económico y basado en una estrategia de atracción de la inversión extranjera que combina importantes inversiones en infraestructura y un agresivo programa de incentivos fiscales. Este movimiento tiene su liderazgo y coordinación en el propio Gobierno de Pernambuco, principalmente a través de su Secretaría de Desarrollo Económico y órganos que están obligados como la Agencia de Desarrollo Económico del Estado de Pernambuco ADDIPER, la propia la empresa SUAPE, directora del Complejo Industrial y Portuario, y el Foro Mundial de Suape como instancia multi-institucional, que contribuiría para la construcción de la visión de futuro del proyecto.

La tensión expansiva, sin embargo, traía un seguro inherente. El que el Territorio estaría sujeto a un alto riesgo de ocupación depredadora con graves impactos sociales y ambientales, y tal vez irreversible. El Foro del Territorio Estratégio de Suape coordinado 
por la agencia CONDEPE / Fidem, la agencia de planificación e investigación del Gobierno de Pernambuco, no era un movimiento de oposición al proyecto de Suape, pero era una respuesta institucional a los riesgos evidentes que serían causados por las inversiones de esta orden en un tiempo tan corto y tan concentrada geográficamente. Su documento guía es el estudio "Directrices para la Ocupación Sostenible de Territorio Estratégico de Suape", publicado en 2008.

Suape traería empleos y riqueza a través de las grandes inversiones públicas y privadas, y cabría Foro del Territorio Estratégico sugerir una ruta que causase menor daño posible y que al mismo tiempo convenciese a la sociedad de Pernambuco que el proyecto seguiría un modelo y un camino sostenible.

La realidad, sin embargo, ha sido abrumadora. Treinta y seis años después de la creación oficial de la empresa Suape Industrial y complejo portuario (CIPS), fundada para administrar el distrito industrial, el desarrollo de las obras y el establecimiento y funcionamiento de las actividades portuarias, parece que hay poco que celebrar. En un reciente artículo escrito para el blog Suape Foro - Espacio Ambiental, profesor de la Universidad Federal de Pernambuco Hector Scalambrini Costa señala que no hubo celebración por parte del gobierno del estado para celebrar 36 años del puerto, a excepción de un informe de la publicidad publicada en el periódico con tono vanaglorioso en el que ensalza sus propios logros y autoelogios, basando su percepción del éxito de la empresa con las cifras de crecimiento económico y la cantidad de complejo de negocios y otros estados. (COSTA, 2014 a)

El profesor Scalambrini continúa en sus observaciones, señalando que para el establecimiento de empresas en el Complejo, comunidades enteras que vivían en aquel lugar durante décadas fueron expulsados. Cerca de 15 mil familias fueron tratados como "invasores", siendo desalojados de forma truculenta y arbitraria de sus casas donde vivieron mucho antes de la primera industria haber instaládose en Suape. La mayoría de ellas ni siquiera recibieron una vivienda alternativa decente. "Direitos foram negados. Promessas não foram cumpridas. Indenizações (quando pagas) foram desprezíveis diante da impressionante valorização das terras (atualmente, em média, um ha vale em torno de um milhão de reais)." (COSTA, 2014 b)

Y no sólo fueron afectadas las poblaciones nativas (pescadores, agricultores, trabajadores). Los residentes de las ciudades circundantes también han sufrido las consecuencias de la falta de planificación y del modelo de ocupación de Suape. La mejora de las condiciones de vida y el enriquecimiento de Pernambuco tan ampliamente publicitado todavía están en el reino de las promesas (Costa, 2014 c), como lo demuestran los indicadores locales de desarrollo humano. El crecimiento de los indicadores económicos no se reflejó en el desarrollo sostenible de la región. La desigualdad ha empeorado:

Expansão sem planejamento, crescimento econômico baseado em um "modelo predador", não inclusivo, com devastação ambiental, com indústrias sujas, continua sendo a marca do complexo de Suape. A atração por indústrias altamente agressoras ao meio ambiente, aliado a perdas e injustiças cometidas (prejuízos, danos físicos e morais, expulsões, expropriações, privações, desgraças, destruições 
de vidas e de bens), muitas delas permanentes e irreversíveis, enseja uma ampla discussão sobre que tipo de desenvolvimento que queremos. (COSTA, 2014 d)

A pesar del volumen y de la importancia de las inversiones en la creación de empleos, el Territorio de Suape se convirtió en una " caldera" del conflicto sociales y un ejemplo emblemático de un territorio con un crecimiento del PIB notable que no pudo evitar que una lógica perversa socioeconómica se instaurase en la región, agravada por las graves amenazas de degradación ambiental del ambiente marino y costero y la precariedad de la vida en las ciudades del territorio.

El escenario es un área que a pesar de tener una propuesta oficial para el desarrollo sostenible se establece en la propuesta de la Agencia CONDEPE / Fidem, está sucumbiendo al nivel estratosférico de las inversiones concentradas en el tiempo y el espacio como en pocos lugares del mundo, generando un profundo foso entre los resultados económicos obtenidos por los grupos nacionales e internacionales, los propietarios de medios de producción y la calidad de vida de las personas que viven alrededor del complejo, generando una sensación generalizada de que la vida se ha agravado en la región.

\section{IMPACTOS ECONÓMICOS Y SOCIALES DE INVERSIONES}

La percepción general es que, en primer lugar, no se puede negar los números. El "boom" de Suape no es un "boom" del desarrollo, pero sin duda hubo un salto extraordinario en la entrada de inversiones en el Complejo, afectando a su alrededor. Los municipios del Territorio pasaron a tener una nueva mirada sobre el desarrollo económico y todos crearon estructuras administrativas para afrontar los retos. $100 \%$ de los municipios tienen Secretaria de Desarrollo Económico e Distrito industrial, aunque estos últimos presenten diferentes grados de desarrollo. En los Distritos Industriales, es posible identificar en el Plan Director de Suape, la intención de crear distritos satélites para recibir empresas complementarias a las cadenas productivas.

Las cifras del PIB de los municipios del territorio no dejan duda sobre el impacto de la inversión de Suape, en el crecimiento económico. Pernambuco tiene 184 municipios, más el territorio administrativo de Fernando de Noronha. Con sólo el 4,3\% de los municipios del estado y el $13 \%$ de la población, el territorio Estratégico de Suape representa el $25 \%$ de toda la riqueza producida en el estado. Solo, Ipojuca, con sólo 90.000 habitantes representa casi el $10 \%$ del PIB de Pernambuco y representa el $40 \%$ del PIB del país.

Comparando la participación del Territorio Estratégico de Suape en el PIB estatal con la participación de las regiones en desarrollo, parece que con la excepción de la Región Metropolitana de Recife, que incluye cuatro de los ocho municipios de la TES, todos tienen participación mucho menor del PIB del Estado ni siquiera tener un mucho mayor número de municipios, como se puede ver en la Tabla 3 - Participación de las regiones de desarrollo y de los TES en el PIB estatal. 
Tabla 3 - Participación de las Regiones de Desarrollo y del TES en el PIB estadual

\begin{tabular}{|c|c|c|}
\hline Región de Desarrollo & № de municipios & Participación en el PIB estadual \\
\hline Agreste Central & 26 & $7,74 \%$ \\
\hline Agreste Meridional & 26 & $3,83 \%$ \\
\hline Agreste Setentrional & 19 & $3,09 \%$ \\
\hline Mata Norte & 19 & $4,03 \%$ \\
\hline Mata Sul & 24 & $5,26 \%$ \\
\hline Región Metropolitana de Recife & 15 & $64,71 \%$ \\
\hline Sertão Central & 8 & $1,09 \%$ \\
\hline Sertão de Itaparica & 7 & $1,33 \%$ \\
\hline Sertão de Araripe & 10 & $1,54 \%$ \\
\hline Sertão de Moxotó & 7 & $1,26 \%$ \\
\hline Sertão de Pajeú & 17 & $1,92 \%$ \\
\hline Sertão de São Francisco & 7 & $4,20 \%$ \\
\hline Total & 185 & $100,00 \%$ \\
\hline Territorio Estratégico de Suape & 8 & $24,58 \%$ \\
\hline
\end{tabular}

Fuente: (Agencia Condepe Fidem, 2014)

Es importante destacar que el Territorio Estratégico de Suape no fue establecido formalmente como un desarrollo del estado de Pernambuco. Él está formado por los municipios de dos regiones de desarrollo. Lo que añade los ocho municipios de TES es la influencia del Complejo Industrial de Suape, aunque formalmente no existe como una región administrativa. Su fuerza económica, sin embargo, es innegable. La participación de TES en el PIB estatal La participación de TES en el PIB estatal es equivalente a la suma de la participación de todo el Agreste y Sertão de Pernambuco. En conjunto, estas dos regiones producen alrededor del 26\% del PIB del estado de la contribución de los 127 municipios.

Tabla 4 - Contribución para el PIB Total del Territorio

\begin{tabular}{lcc}
\hline \multicolumn{1}{c}{ Municpio } & PIB 2012 (R\$ Millón) & $\begin{array}{c}\text { Contribuye para el } \\
\text { PIB del TES }\end{array}$ \\
\hline Cabo de Santo Agostinho & 6.006 & $20,83 \%$ \\
Escada & 529 & $1,83 \%$ \\
Ipojuca & 11.596 & $40,21 \%$ \\
Jaboatão dos Guararapes & 9.480 & $32,87 \%$ \\
Moreno & 386 & $1,34 \%$ \\
Ribeirão & 282 & $0,98 \%$ \\
Rio formoso & 205 & $0,71 \%$ \\
Sirinhaém & 354 & $1,23 \%$ \\
\hline
\end{tabular}

Fuente: (Condepe Fidem, 2014 a)

La contribución en la constitución del territorio Suape del PIB, sin embargo es muy irregular (Tabla 4). Ipojuca, Jaboatão dos Guararapes y Cabo de Santo Agostinho representan casi $94 \%$ del PIB del territorio, lo que demuestra el nivel de concentración 
violenta de las inversiones, sobre todo en los municipios de Ipojuca y Cabo de Santo Agostinho, ya que el Jaboatão dos Guararapes, según más poblado de Pernambuco, con cerca de 700.000 habitantes, tiene otros factores que explican su producción de riqueza. Es un municipio con un alto nivel de conurbación con la capital Recife, siendo muchas veces imposible, "a simple vista" separar geográficamente las dos ciudades.

El Ipojuca participa con el $40 \%$ del PIB del territorio, casi el doble del Cabo de Santo Agostinho. Esto se explica geográficamente. El propio puerto de Suape pertenece a Ipojuca. Las grandes inversiones como la refinería, complejo petroquímico Abreu e Lima y todos los sitios están en suelo ipojucano.

Todavía en el campo del análisis económico, otro índice que muestra el impacto de las inversiones del Complejo de Suape en el territorio, es el PIB Per Cápita (Cuadro 5). Evaluado isoladamente, el PIB Per Cápita del território de Suape llegó en 2012 a R \$ 23.843, más que el PIB de la Región Metropolitana de Recife que se situó en poco más de veinte mil reales y mucho más alto que el promedio del estado que es de poco más de 13.000. Cabe destacar también el hecho de que el PIB Per Cápita en el municipio de Ipojuca, además de ser el más grande del estado, es de aproximadamente seis veces mayor que la del capital Recife y aproximadamente diez veces mayor que la del estado, lo que demuestra más una vez que el impacto de las inversiones y su alta concentración geográfica.

Tabla 5 - PIB Per Cápita por Región de Desarrollo y Territorio de Suape

\begin{tabular}{lr}
\hline Región de Desarrollo & PIB Per Cápita (R\$ \\
Millón)
\end{tabular}

Fuente: (Condepe Fidem, 2014 b)

\subsection{La creación de riqueza y su distribución en el territorio}

Con base en los datos del Atlas de Desarrollo Humano en Brasil, se observa que la renta per cápita media del Territorio Estratégico de Suape, creció $119,75 \%$ en las últimas dos 
décadas, pasando de $R \$ 168,67$ en 1991 a $R \$ 23901$ en 2000 y $R \$ 370,65$ en 2010. La proporción de personas pobres, es decir, con renta familiar per cápita inferior a $R$ \$140,00 (precios de agosto de 2010) aumentó de $67,09 \%$ en 1991 a 52,90\% en 2000 y $27,46 \%$ en 2010. La evolución de la desigualdad de ingresos en estos dos períodos puede ser descrita por el índice de Gini, que pasó de 0,52 en 1991 a 0,55 en 2000 y 0,50 en 2010.

A pesar de la mejora significativa en las últimas dos décadas la renta per cápita del Territorio Estratégico de Suape (Figura 1), es muy inferior a la renta per cápita del Estado de Pernambuco, que en 2010 fue de $R \$ 525,64$, y el Nordeste, que fue de $R \$ 470,75$ en el mismo año. Otras comparaciones dejan esta diferencia aún más evidente. La renta per cápita de la región metropolitana de Recife, en 2010 fue de $\mathrm{R} \$$ 780,36, por lo que el 105\% más alto que el ingreso del Territorio de Suape. En relación con la renta per cápita medida en Recife, el ingreso de los TES es sólo el 32\% de R \$1,144.26 de la capital. (PNUD, 2013 a)

Gráfico 1 - Comparación de la renta per cápita de los municipios del Territorio Estratégico de Suape (TES) con media estadual

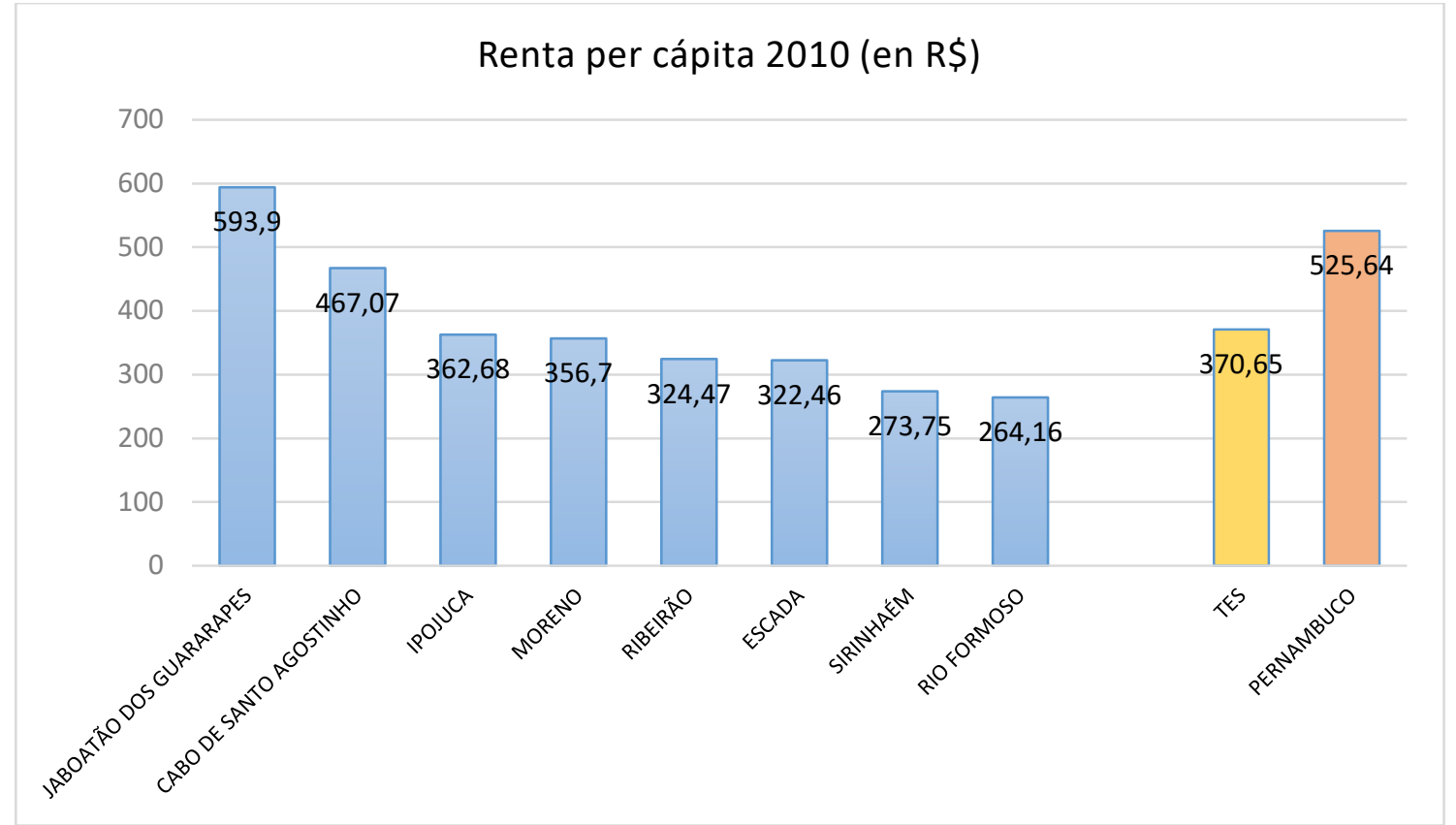

Fuente: (PNUD, 2013 b). (Elaboración del autor)

El Atlas de Desarrollo Humano en Brasil (PNUD, 2013 c) refuerza esta percepción demostrando que el municipio de Ipojuca, epicentro del "boom" de Suape, a pesar de haber alcanzado una remuneración promedio de 4.3 salarios mínimos en 2010, más de 84 $\%$ de la población recibe menos de dos salarios mínimos, lo que confirma que la gran mayoría de la población no ha sido ayudada por el aumento de la producción de la riqueza en la ciudad. Las proporciones son similares en todo el territorio, cuyos trabajadores promedio con un máximo de dos veces el salario mínimo es de $85,11 \%$ (Gráfico 3). Las cifras son ligeramente peor que la proporción de trabajadores em Pernambuco $(81,70 \%)$ y mucho peor que la relación de la Región Metropolitana de Recife, con alrededor del 73\% 
de los trabajadores en este rango de salario. Las cifras no dejan lugar para uma observación diferente, sino pensar igual que el investigador:

(...) embora tenha ocorrido um intenso crescimento da riqueza produzida na região, como destaca o incrível aumento do PIB, essa não vem sendo redistribuída na mesma proporção, velocidade e magnitude. (...) a maior parte da população mantém faixas salariais muito baixas, inferiores às médias do estado e do país. (GODOY, 2014 a)

A pesar de la mejora en el ingreso promedio per cápita de los hogares han mejorado en los últimos años, su evolución en comparación con el nivel de las inversiones en el Complejo, uno ve una disparidad profunda y altos niveles de concentración de los salarios más altos. Sólo el 2,94\% de los trabajadores empleados en el territorio Estratégico de Suape reciben salarios por encima de cinco salarios mínimos. (PNUD, 2013e).

Gráfico 3 - \% de los ocupados con ingreso de hasta 2 salarios mínimos

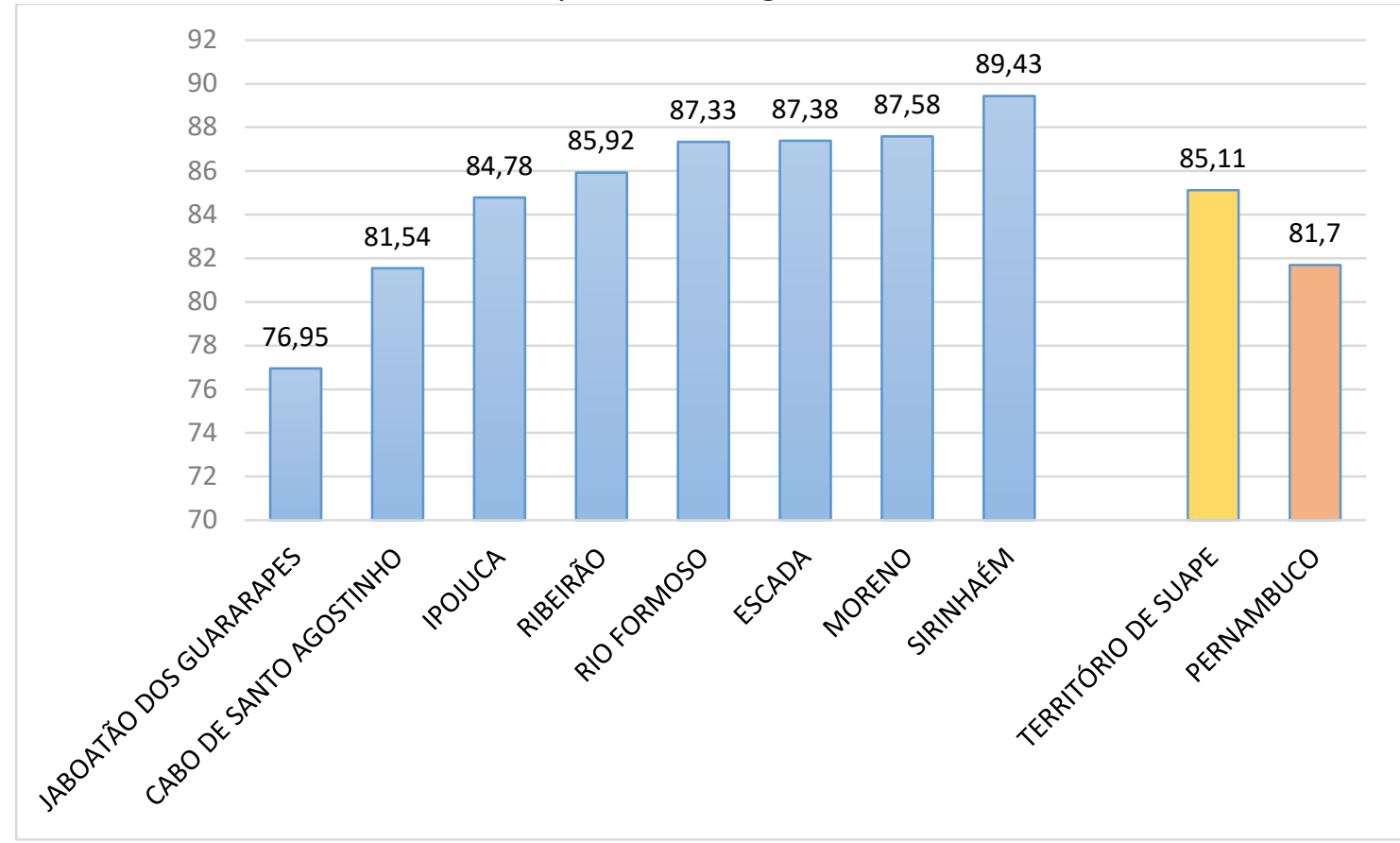

Fuente: (PNUD, 2013 d). (Elaboración del autor)

\subsection{La evolución del desarrollo humano en el Territorio Estratégico de Suape}

La evolución de IDHM de los municipios de Territorio Estratégico de Suape siguió la tendencia ascendente de las últimas dos décadas se observan en todo el Brasil. (Figura 1). En 1991, casi el 86\% de los municipios brasileños estaban en el rango de IDH "muy bajo". En 2000, el número de municipios con IDH "muy baja" se redujo a 41,8\% y en 2000 y 2010 son sólo el $0,6 \%$ de los municipios en este rango. La proporción de municipios en el rango de IDH "Medium" pasó de 0,8\% en 1991 al 26,1\% en 2000, y en 2010 alcanzó el 40,1\% de los municipios brasileños. En 1991 ningún municipio en el país alcanzó el nivel de IDH de 
"alto". En el año 2000 esta cifra ya 2,4\% era y en 2010, 33,9\% de los municipios de Brasil llegó a esta pista. (PNUD, 2013 f)

El crecimiento del IDH en los municipios del territorio estratégico de Suape, por lo tanto, que no se destacan de la tendencia y el crecimiento promedio del IDH-M de los municipios del Brasil. Además, la mayoría de los municipios del territorio, incluso lograron llegar a los números de Pernambuco, con la excepción de Jaboatão dos Guararapes y Cabo de Santo Agostinho, los miembros de la Región Metropolitana de Recife. En promedio, el IDH del Territorio en 2010 fue de 0.640, mientras que el Pernambuco alcanzó 0.673 en 2010, el IDH considerarse sólo "medio".

Tabla 6 - IDHM 2010 los municipios de TES

\begin{tabular}{|c|c|c|c|c|c|}
\hline $\begin{array}{c}\text { Ranking } \\
\text { Brasil }\end{array}$ & Municipio & $\begin{array}{c}\text { IDH-M } \\
2010\end{array}$ & $\begin{array}{c}\text { IDH-M } \\
\text { Renta } \\
2010\end{array}$ & $\begin{array}{c}\text { IDH-M } \\
\text { Longevidade } \\
2010\end{array}$ & $\begin{array}{c}\text { IDH-M } \\
\text { Educación } \\
2010\end{array}$ \\
\hline 1398 ㅇ & Jaboatão dos Guararapes & 0,717 & 0,692 & 0,83 & 0,642 \\
\hline 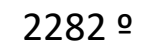 & Cabo de Santo Agostinho & 0,686 & 0,654 & 0,812 & 0,609 \\
\hline 3721 ㅇ & Ipojuca & 0,619 & 0,613 & 0,774 & 0,499 \\
\hline 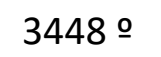 & Escada & 0,632 & 0,594 & 0,781 & 0,543 \\
\hline 3070 ㅇ & Moreno & 0,652 & 0,61 & 0,805 & 0,564 \\
\hline 4101 ㅇ & Ribeirão & 0,602 & 0,595 & 0,711 & 0,516 \\
\hline 4215 ㅇ & Sirinhaém & 0,597 & 0,568 & 0,763 & 0,492 \\
\hline 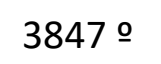 & Rio Formoso & 0,613 & 0,562 & 0,809 & 0,506 \\
\hline
\end{tabular}

Fuente: (PNUD, $2013 \mathrm{~g}$ )

En el ranking IDHM estado, las ciudades de Territorio Suape Estratégico no logran sobresalir en su mayoría. Jaboatão dos Guararapes (5) y el Cabo de Santo Agostinho (8) son las excepciones y pueden estar entre los diez primeros en el estado. A continuación se presentan Moreno (23) y Escada (36), pero ya lejano de los diez primeros; Ipojuca, con todo el vigor del PIB Per Cápita diez veces mayor que la de Pernambuco, sólo ocupa la posición número 43 del estado rango, e incluso más atrás Formoso río y Sirinhaém ocupar la 70a y la posición 85a. (CONDEPE FIDEM, 2013)

Al confrontar la evolución de las cifras de IDH de Territorio Estratégico de Suape enumerados anteriormente, con los niveles de inversión alcanzados en la región, especialmente en el complejo portuario, principalmente en relación con el aumento del PIB y el PIB per cápita es claro que "as melhorias nos indicadores de desenvolvimento humano não ocorreram na mesma magnitude e velocidade que o crescimento da riqueza produzida na região". (GODOY, 2014 b)

Una vez más se puede observar que, incluso delante de las mejoras en las condiciones de vida promedio de la población local, hay una tendencia que está favoreciendo el crecimiento económico. Ipojuca, que concentra la mayor parte del crecimiento económico de la región, aunque tenga alcanzado el segundo mayor PIB del estado y uno de las más altas rentas per cápita del PIB en el país, no alcanzó el nivel 
promedio de IDH de Pernambuco y se mantiene lejos de la media nacional. (GODOY, 2014 c)

Un aspecto que llama la atención en la Tabla 6 - IDH 2010 de los municipios de TES - son los bajos niveles del IDH Educación para todos los municipios del Territorio Estratégico de Suape. Ipojuca es uno de los más bajos entre las ocho ciudades. Sólo Jaboatão dos Guararapes y Santo Agostinho alcanzaron el nivel "Medio". Escada, Moreno, Ribeirão y Rio Formoso están con índices considerados "bajos" y Ipojuca y Sirinhaém con índices "muy bajo".

Figura 1 - Evolución del IDH-M en Brasil

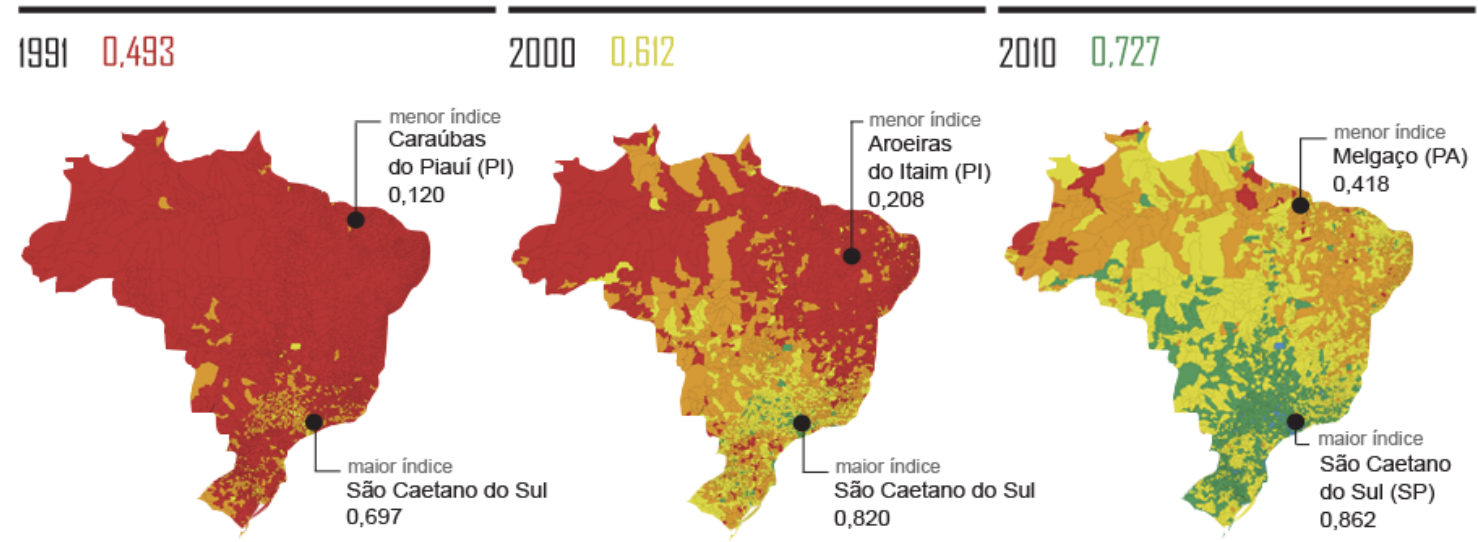

\% DE MUNICÍPIOS POR FAIXA DO IDHM
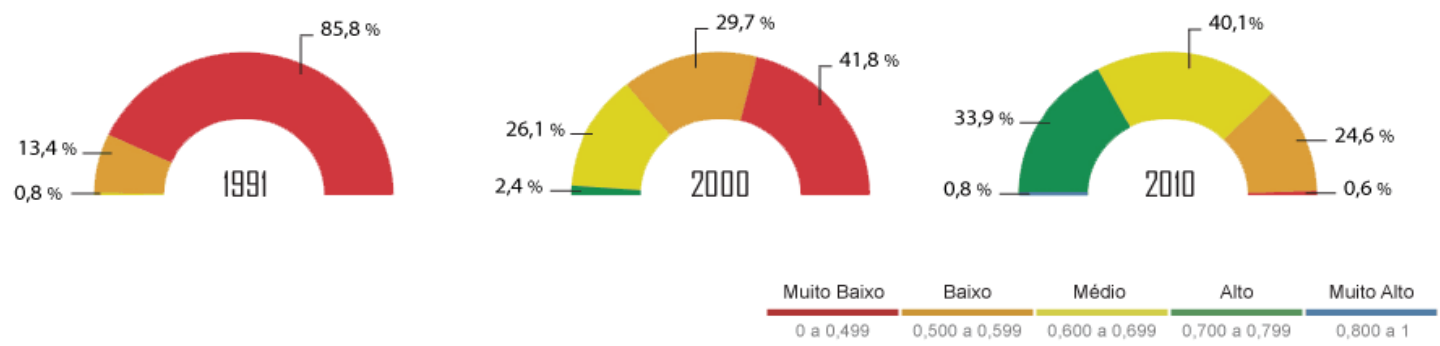

Fuente: Atlas del Desarrollo Humano (PNUD, 2013 h)

De nuevo llega la aparente desconexión entre la producción de riqueza en el territorio y la calidad de vida de la población. A pesar de tener el segundo mayor PIB y el primer mayor PIB per cápita de Pernambuco Ipojuca, por ejemplo, no se puede mover proporcionalmente en los otros índices y tiene uno de los peores índices de desarrollo humano en la dimensión educativa del Territorio Estratégico de Suape, que, en promedio, también no va mucho más allá de un nivel "bajo" en la educación del IDH.

La concentración de las inversiones millonarias, la aparición de nuevas cadenas productivas, la generación de miles de empleos y el aumento del producto interno bruto del estado y las ganancias del "efecto Suape", no parecen suficientes para tener un impacto positivo, en las mismas proporciones, el desarrollo humano que rodea el 
Complejo Portuario. Aunque con el avance del IDH entre 1991 y 2010, la mayoría de las ciudades que conforman el territorio son todavía muy por debajo de los mejores índices del propio estado de Pernambuco y Brasil, como se muestra en la figura 4.

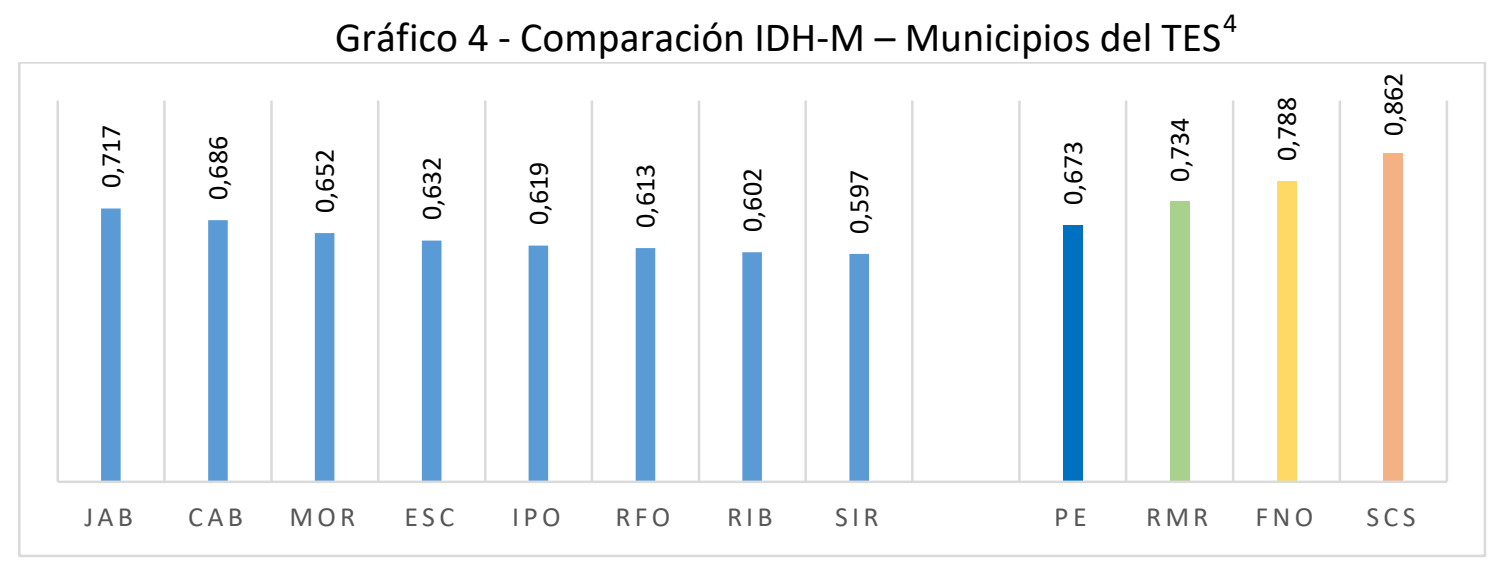

Fuente: Atlas del desarrollo humano (PNUD, 2013 i)

\section{EL ENTORNO EMPRESARIAL Y EL ESPIRITÚ EMPRENDEDOR}

Uno de los aspectos emblemáticos de la expansión de Suape es la creación de puestos de trabajo y oportunidades. La estrategia claramente enfocado para atraer grandes inversiones, se convirtió en el ambiente de negocios hostil para los nuevas y pequeñas empresas de Pernambuco. Algunos mismos segmentos inhibidos en el proceso de adhesión al régimen fiscal de la Simples Nacional, a priori ventajosa para las pequeñas empresas, pero cuyos beneficios fueron cancelados antes de la política fiscal del estado, en cierto modo, compensaba con recorridas de las MPEs, la renuncia de impuestos realizada en favor de los grandes negócios.

La estrategia se basa sobre todo en un programa de incentivo fiscal agresivo que ha sido protagonista en el esfuerzo para atraer la inversión extranjera al estado. El Programa de Desarrollo del Estado de Pernambuco (PRODEPE), comprende un conjunto de incentivos fiscales específicos para algunos sectores de la actividad económica, entre las que destacan: industrial, centro de distribución e importador mayorista, bajo la responsabilidad de la Agencia de Desarrollo Económico de Pernambuco - ADDIPER.

El programa ha existido desde 1999 y fue establecido por la ley $n{ }^{\circ} 11.675$, de 11 de octubre, 1999 y reglamentada por el Decreto ${ }^{\circ} 21959$ de 27 de diciembre de 1999. Desde entonces, el texto de la ley ha sido objeto de al menos veinte cambios, uno de los más relevantes el establecido por la Ley 13.280 del 17 de agosto de 2007, que transformó el programa de presuncíon de crédito, en palabras de su propio ADDIPER, "em um dos

\footnotetext{
${ }^{4}$ Leyenda: JAB: Jaboatão dos Guararapes; CAB: Cabo de Santo Agostinho; MOR: Moreno; ESC: Escada; IPO: Ipojuca; RFO: Rio Formoso; RIB: Ribeirão; SIR: Sirinhaém; PE: Pernambuco; RMR: Região Metropolitana do Recife; FNO: Fernando de Noronha (maior IDH-M de Pernambuco); SCS: São Caetano do Sul (Maior IDH-M do Brasil).
} 
programas estaduais mais robustos do gênero, pela abrangência e escalonamento de percentuais em função da localização dos empreendimentos. "

Gráfico 5 - Empleos generados e Investimentos en el ámbito del PRODEPE (2007 a 2013)
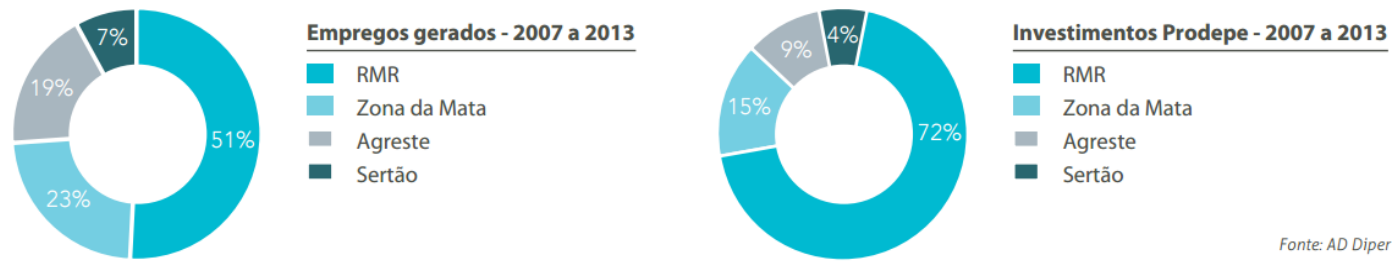

Fuente: (ADDIPER, 2014)

Según cifras de ADDIPER, de 2007 a 2013, el PRODEPE contabilizó 714 proyectos industriales para el Estado, de generación estimada de 68.750 puestos de trabajo (Gráfico $5)$. Las inversiones llegaron a alrededor de $\mathrm{R} \$ 18,5$ mil millones y fueron distribuidas en todas las regiones de desarrollo. En 2013, 65 de las 33 empresas optaron por la ejecución o ampliación de plantas en los distritos del interior, casi el 51\% del total, mientras que la región metropolitana de Recife (RMR) ocupan los otros proyectos. (ADDIPER, 2014)

Pernambuco se había convertido en una obra de construcción en la expresión del gusto de los dirigentes políticos, y saludó a la gente con la promesa de empleo para todos y salarios jamás cometido en el estado. En 2010, el periodista Murillo Camarotto publicado en el periódico Valor Econômico, el artículo titulado "No Nordeste, cortador de cana vira soldador." A pesar de la referencia al noreste, el asunto está totalmente orientado a Pernambuco, y más concretamente los empleos generados por Suape.

\subsection{El espíritu empreendedor y la competitividad de las empresas locales}

Un aspecto importante de una oferta de empleo que se produjo en Pernambuco, es la forma en que afecta a la velocidad de la iniciativa empresarial (creación de empresas) y la competitividad de las empresas locales.

El estado adoptó una estrategia local de característica muy furte top down, es decir, la política centralizada, implantados arriba y abajo con poca o ninguna participación de la administración local (en estos casos, municipales) de la "creencia" de que el desarrollo de un centro rico y próspero será capaz de irradiar su riqueza para las zonas desfavorecidas. Para lograr este objetivo, el Complejo Puerto de Suape abrió indiscriminadamente sus puertas a la capital, sin una política de selección y prioridad, sobre la base de una estrategia que ha sido objeto de críticas por parte de expertos que demuestran la tensión entre el deseo de incluir la mayor cantidad de empresas ya que muchos son posibles y la necesidad de conciliar con una política pública eficaz. (PIKE, et al., 2011 a). Las políticas top down, sin embargo, ha demostrado ser incapaz de generar procesos de desarrollo sostenible.

Uno de los problemas está en la transferencia de recursos (capital, tecnología, mano de obra calificada) entre zonas desarrolladas y menos desarrolladas. Esta ecuación no es fácil y los resultados pueden causar disfunciones que reducen aún más el potencial 
de desarrollo en las regiones desfavorecidas cambiando el funcionamiento del mercado de trabajo. Este tipo de trastorno se deriva del hecho de que la concentración de la inversión y recursos genera una especie de dualidad económica implica la marginación de los mercados de trabajo en las zonas desfavorecidas. Estas áreas no tienen acceso a los recursos y los extremos de la fuerza laboral locales especializadas en actividades rutinarias que no requieren mano de obra calificada.

Otro aspecto importante que afecta al modelo basado en la atracción de inversión extranjera como el principal desarrollo de recursos, es que las decisiones estratégicas se toman fuera del território, en la sede corporativa. La mayoría de las empresas atraídas por la conjuntura Suape, participan en grandes grupos internacionales y, por lo tanto, las decisiones estratégicas, tales como componer un desarrollo territorial sostenible, no se toman a nivel local.

Todos estos factores actúan juntos, afectar negativamente a dos aspectos que son fundamentales para el desarrollo sostenible del territorio: inhiben la creación y consolidación de nuevas empresas y frenan el proceso de difusión de la tecnología, retardando el proceso de formación de una cultura local el desarrollo empresarial y la competitividad empresarial del territorio.

El artículo de Silva Lira Desarrollo Local Competitividad territorial y en América Latina, publicado en 2005, ya se puso de relieve la importancia y la necesidad de plantillas de diseño institucional y estilos de gestión pública que faciliten la aplicación de las políticas de desarrollo productivo que señalen la creación de un entorno empresarial más competitivo para las empresas locales. (LIRA, 2005 a)

El fortalecimento de entorno empresarial depende de una acción transversal de las distintas fuerzas que intervienen en el proceso de organización y planificación territorial y local, a fin de permitir la estructuración o reestructuración de un entorno institucional favorable a la aparición de nuevos negocios y la consolidación de las empresas existentes.

Cuando se habla de la transformación de los sistemas productivos locales, vamos a hablar acerca de lo que debe hacerse para mejorar la capacidad competitiva de las empresas locales (LIRA, 2005 b). Pero, si estas empresas hacen en su mayoría absoluta de micro y pequeñas empresas, como ha demostrado varios estudios de todo el mundo, en la práctica se está mejorando la competitividad de este segmento que se está hablando.

\subsection{El caso de Ceará. Una constatación.}

La evaluación de todos estos factores, y sus efectos nocivos para la formación de una cultura de desarrollo empresarial local, parece que hay indicios muy significativos que el ritmo de creación de nuevas empresas en Pernambuco se vio afectada considerablemente, como se muestra en la comparación entre el número de Pernambuco y el Estado de Ceará, la tercera economía más grande en el Nordeste, por así decirlo, el principal y más cercano competidor en la carrera de la generación de riqueza en la región, ya que el estado de Bahía tiene una ventaja mayor.

Entre 2009 y 2012, el PIB de Pernambuco siempre fue significativamente mayor que el de Ceará, con ventajas siempre por encima del 15\%. En 2012 el PIB de Pernambuco fue aproximadamente $23 \%$ más alta, superando el estado vecino en más de 27 mil 
millones de reales (Gráfico 6). Se esperaba que el estado de la economía más robusta había crecido en proporción a su número de empresas, sin embargo, los números indican diferente tendencia, sobre todo en la época dorada de la creación de empleo en Suape, con el inicio de los grandes proyectos de los anuncios de los grandes y inversiones.

Con la promulgación del Estatuto de la Micro y Pequeña Empresa en Brasil (Ley Complementaria 123/2006), y la creación de un Sistema Simplificado de Tributación, el Simple Nacional, Brasil inició un camino fundamental para el fortalecimiento de la economía nacional a través de la regulación de trato diferenciado y favorecido a micro y pequeñas empresas, según lo dispuesto por la Constitución Federal de 1988. A partir de ese momento comenzaron en todo el país un gran movimiento de creación de nuevas pequeñas empresas, una trayectoria meteórica del crecimiento en el país dejó 2,8 millones de empresas que optan la simple Nacional en 2007 hasta 9,5 millones en 2014.

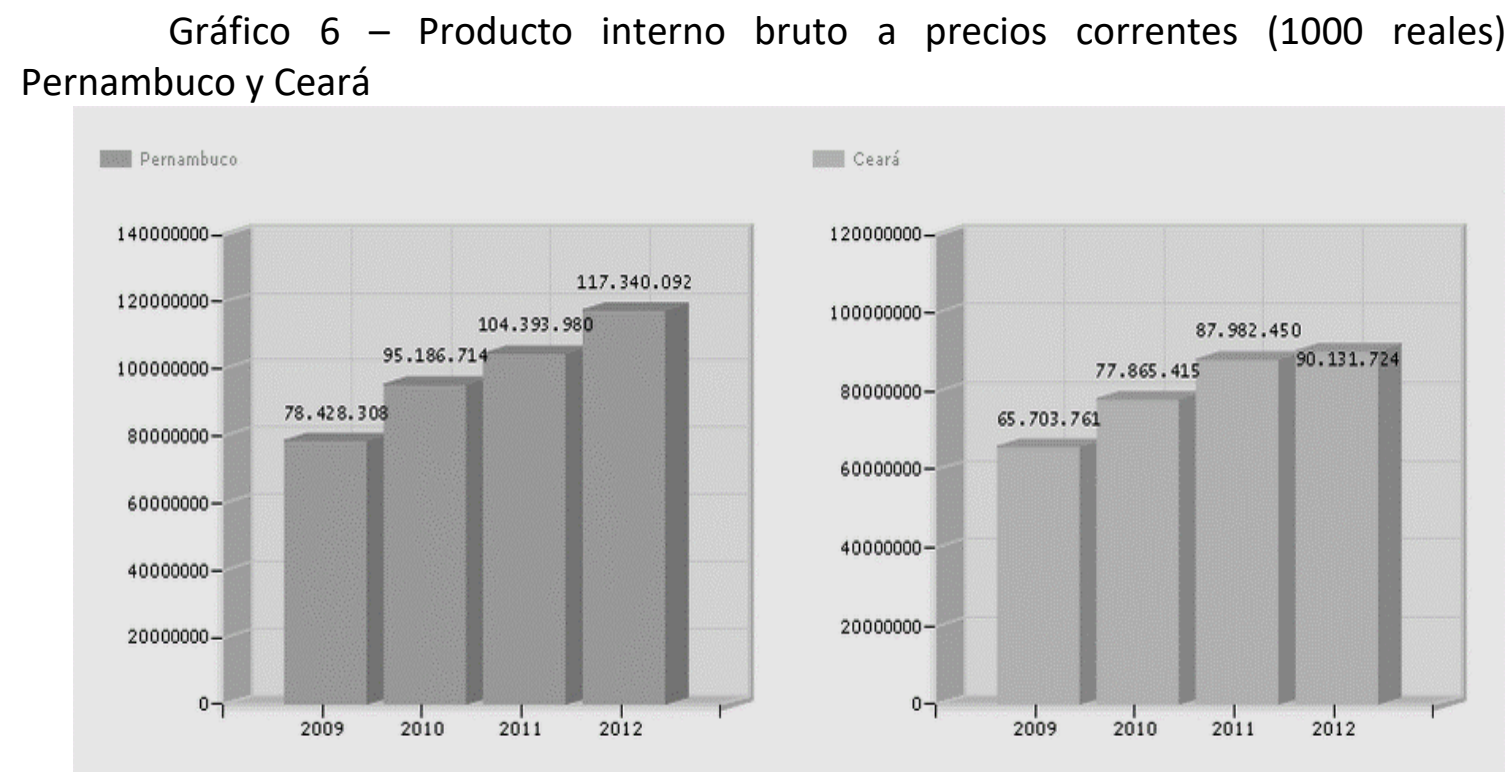

Fuente: (SEBRAE - NÚCLEO DE INTELIGÊNCIA TERRITORIAL - NIT, 2015)

A pesar de tener una economía más fuerte y todo estímulo que debe suponer para la creación de nuevas empresas el optimismo generado por la llegada de grandes inversiones, no se confirmó esta tendencia. En 2007, por ejemplo, el año puso en el PRODEPE y comenzó el gran programa de atracción de jóvenes y adultos para trabajar en el astillero y la refinería, Ceará ya tenía 103.000 pequeñas empresas siendo favorecidos por el nuevo régimen fiscal, Pernambuco solamente ha ido más allá de la casa de 50.000 empresas. (Gráfico 7) 


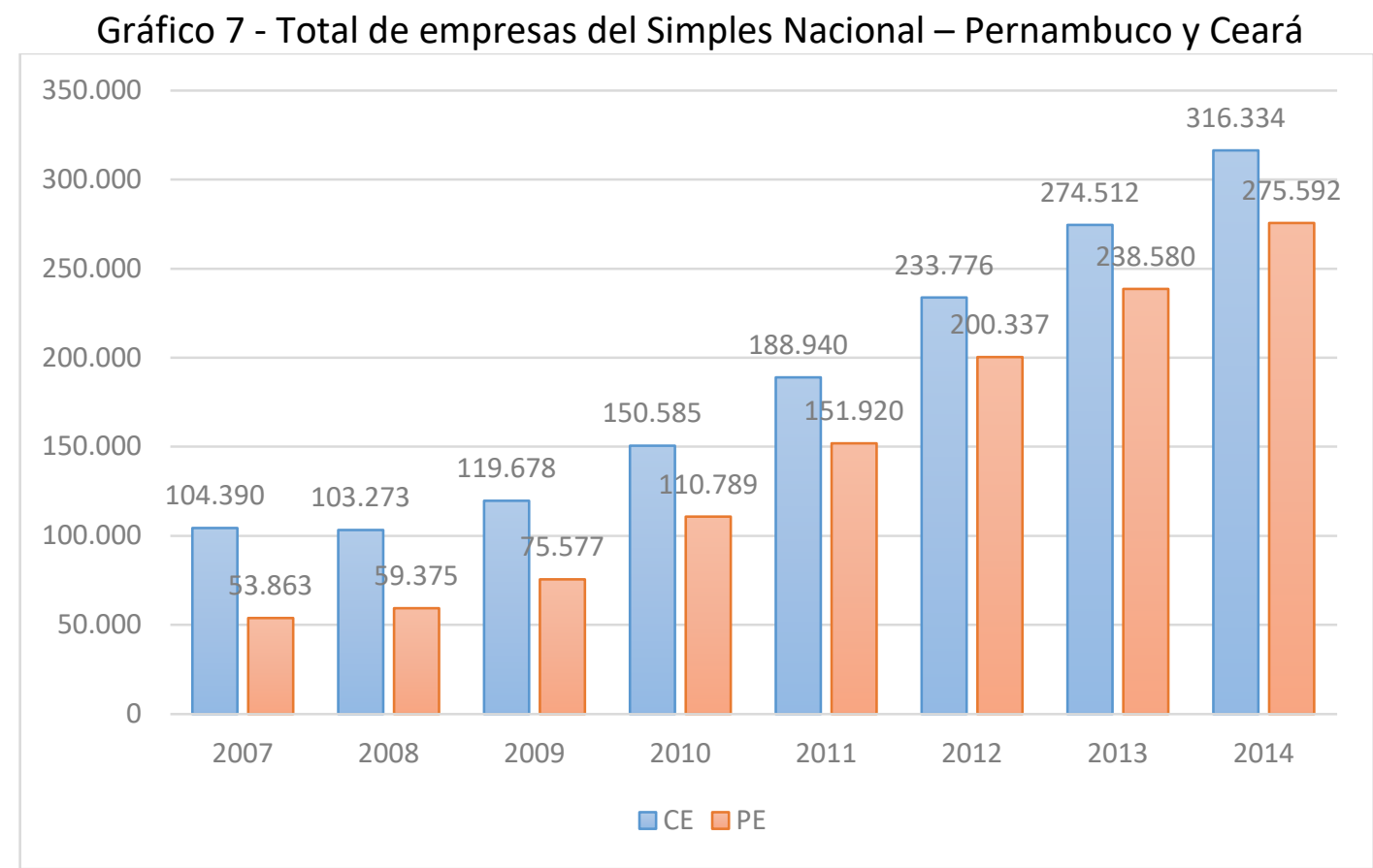

Fuente: (RECEITA FEDERAL, 2015)

En 2009, cuando Pernambuco había llegado a 75.000 pequeñas empresas, Ceará ha acercado al 120.000 optantes del Simple Nacional. Es de destacar que este año el PIB de Pernambuco fue 16\% mayor que el de Ceará. En 2010, finalmente, Pernambuco rompió la barrera de los cien mil empresas, alcanzando valores cercanos a aquellos que poseían el Ceará desde 2007, es decir, poco más de 110 mil optantes. Ese mismo año, el estado de Ceará llegó a la casa de las 150000 empresas en el nuevo régimen. Es de destacar que, incluso con un PIB inferior al 18\% en 2010, Ceará tenía 40.000 pequeñas empresas que optan por el Simples Nacional a más de Pernambuco.

La diferencia se mantuvo durante los años y el final de 2014 el estado de Ceará alcanzó 316.000 optantes del Simple, contra 275.000 de Pernambuco, es decir, 41.000 empresas a menos aprovechando las ventajas del régimen unificado, opción esta que las hace menos competitivas en el mercado.

\subsection{Ambiente fiscal}

Hacer el escenario aún más difícil para los MPEs, dos mecanismos establecidos por la máquina de recaudación de impuestos del Estado de Pernambuco, la anticipación y sustitución de impuestos, penalizan y presionan los pequenos negocios de manera muy importante, y con una fuerte influencia en la creación de un entorno institucional hostil y crecimiento reprimido para las micro y pequeñas empresas.

La anticipación de impuestos por el pago anticipado del IVA en los casos de adquisición de bienes hechos en otra Unidad de la Federación por los contribuyentes del Estado de Pernambuco, con independencia del régimen de inscripción del comprador. (PERNAMBUCO, 1991). 
La anticipación del impuesto, considerado por muchos expertos legales como inconstitucionales, anticipa un pago que sólo debe ocurrir durante la exportación de las mercancías, evitando el efecto acumulado del impuesto, es decir, evitando que la misma mercancía que hay doble pago de impuestos. Para las empresas del Simple Nacional, la anticipación del impuesto ICMS se suma a los impuestos recaudados en una sola pestaña y calculado sobre los ingresos brutos de la empresa, respondendo a la regla del Simple Nacional, recayendo "en clara y flagrante doble imposición de impuestos". (MONITOR MERCANTIL, 2014)

La sustitución de impuestos es un régimen que concentra la recaudación de impuestos en una etapa de la cadena de la mercancía. A pesar de ser un medio eficaz para las autoridades tributarias, sin embargo, sob a ótica empresarial, puede, en algunos casos los costos de la carga, afectar negativamente la rentabilidad y la competitividad y sopesar los costos y los precios, reduciendo la competitividad. La sustitución de impuestos, en muchos casos también conduce a la doble fiscalidad, de forma similar a lo que sucede a la anticipación de impuestos de la frontera, ya que el impuesto pagado por sustitución, no se puede acreditar de nuevo a la empresa y, por lo tanto, cuando el momento del pago del ICMS del Simples Nacional, la empresa va a pagar de nuevo, ya que el cálculo se lleva a cabo, como hemos visto, sobre la base de los ingresos brutos anuales.

El efecto combinado de todos estos factores contribuyen al ambiente de negocios se convirtió en hostil a la pequeña empresa y, por lo tanto para la iniciativa empresarial y la consolidación de nuevas empresas y redes empresariales locales. El Estado de Pernambuco se rinde a mantener el nivel de almacenamiento con los MPEs que, en cierto modo, ayuda a compensar la renuncia fiscal adoptadas para la atracción de las grandes empresas, haciendo uso de una estrategia que parece ser lo contrario de la adoptada por el mítico Inglés héroe Robin Hood que robaba a la nobleza para dar a los pobres.

\section{GOBIERNO Y GOBERNANZA}

Tomando nota de los escenarios de las decisiones relacionadas a la política de desarrollo del territorio estratégico de Suape, la figura del Gobierno del Estado aparece como el gran protagonista, un centralizador y gestión exclusiva que no contribuyó a la creación de espacios para la construcción de un nuevo modelo de gobernanza más ajustado a las nuevas políticas de desarrollo "de arriba abajo". Y de hecho no era de esperar que esto sucedese, ya que el modelo elegido era típicamente "top down", "de abajo arriba", por todo lo que aquí fue informado.

La falta de autonomía de los municípios sede del Complejo, en las decisiones relacionadas con el plan de ocupación Suape convirtió quejas en actos públicos por parte de los alcaldes y secretarios que llegaron a declarar que no eran consultados por las decisiones a nivel estratégico, dejando el municipio gestionar procesos accesorios relacionados con la atracción de inversiones, tales como la exención de impuestos municipales, ser ágiles en la concesión de licencias para no obstaculizar los planes del Porto y, entre otras obligaciones, recoger los residuos producidos por las industrias. 
Los riesgos de una política así, en cambiarse em rehén del poder económico de las grandes empresas es demasiado alto, ya que no presentan el equilibrio de otros sectores de la sociedad en los debates y en el establecimiento de prioridades, abriendo el campo para los abusos y para la corrupción, que viene siendo denunciados en los últimos tiempos. El gobierno se convierte en un objetivo fácil de los grandes conglomerados y grupos económicos que tienen sus intereses asistidos no ahoran esfuerzos ni recursos para obtener los permisos de trabajo y licencias de operación de sus proyectos que dependen de las autoridades políticas. Esto crea un círculo vicioso y muchas veces, uma relación promiscua y no transparente entre los gobiernos y las empresas. Desafortunadamente, el liderazgo político a cada día pierden su representación y reconocimiento. Las decisiones rara vez se inspiraron en un proyecto de desarrollo real, sino atiende intereses privados en un intercambio de favores e influencias sin fin, que no considera otra prioridad que la suya.

El cambio de gobierno a la gobernanza implica la participación de nuevos actores en la formulación de políticas, dado que las redes se amplían para incluir nuevos grupos, incluyendo organizaciones no gubernamentales, que trabajan para alcanzar las metas y objetivos políticos. (PIKE, et al., 2011 b). Los líderes políticos, sin embargo, a menudo perciben en este movimiento una amenaza, ya que sus prioridades están vinculadas principalmente al mantenimiento de sus mandatos y la conquista de otras posiciones. "La cooperación social que reúne a los sectores público, voluntarios y comunitarios de representantes de la sociedad y de los ciudadanos, sin embargo, son esenciales para el concepto de gobernanza y ha contribuido al establecimiento de las prioridades sociales y económicas." (PIKE, et al., 2011 c)

El territorio Estratégico de Suape no pudo escapar a la regla de la mala política. Aunque un sofisticado plan ha sido desarrollado para evitar o al menos minimizar los impactos ambientales y sociales, son muchas las narrativas de presión del poder económico para agilizar los permisos y licencias de ocupación y funcionamiento, la extorsión política y servidores a los empresarios, y por otro lado hay ofertas que no son éticas de empresarios a gestores y líderes políticos para burlar la ley. Estos procesos no sólo violan la ley, pero hacen una planificación para el desarrollo territorial sostenible.

La falta de redes representativas en el territorio estratégico de Suape, excluyó de las decisiones muchos grupos, de los pescadores y residentes, a propietarios de negocios de las pequeñas empresas, los padres y madres que vieron a sus hijas adolescentes embarazadas de los trabajadores de las grandes obras y una legión de trabajadores que han enfrentado condiciones degradantes de trabajo, generando un clima de conflicto permanente en las grandes obras del complejo. ¿Será que los lugares como la pequeña Gaibu, una de las playas de la ciudad de Cabo de Santo Agostinho, que en pocos años ya no es un lugar agradable y tranquilo para los turistas que optan por convertirse en un lugar deprimido, de lo cual los turistas huyen? Un artículo publicado en 2013 por G1 PE denuncia: 
"Comerciantes e empresários da praia de Gaibu, no Cabo de Santo Agostinho, Região Metropolitana do Recife, afirmam que a economia local está sendo afetada pela falta de estrutura e planejamento e, desse modo, afastando os turistas.

A estrutura da cidade não suportou o inchaço populacional que veio com o desenvolvimento dos municípios do entorno. Problemas como esgoto espalhado pela rua desaguando no mar, obras intermináveis de saneamento básico e construção de casas sem fiscalização são constantes para a população.

Dona Alícia, espanhola que mora em Gaibu há oito anos, afirma ter saudades de quando as ruas não eram tão movimentadas. Para ela, Gaibu está em coma: sem turistas e precisando de mais cuidados. "O turista que entra na cidade já vê que não é um lugar para viver", conta dona Alícia. (G1 PE, 2013)

¿Será que los residentes desplazados de la región, pescadores de varias generaciones optan por abandonar sus sitios de playa y la vida libre, para vivir en aldeas de piedra y cemento? ¿Será que ellos cambiarían sus capturas por un trabajo en la ciudad? ¿Y los dueños de pequeñas empresas? ¿Como si posicionariam en un foro verdaderamente incluyente para todos los sectores y segmentos? ¿ Será que ellos estarían de acuerdo con la elevada presión fiscal asumida por empresas locales, mientras que el Estado otorga presunción de crédito de ICMS de hasta el 95\% para los gigantes del capitalismo global? ¿Era la estrategia correcta? Hoy, que cuentan con el aumento de la violencia, con el consumo de drogas y con el embarazo no deseado de su adolescente tomaría las mismas decisiones?

Tal vez nunca tendremos respuestas a la mayoría de estas preguntas. Pernambuco no creó este espacio, no fomentó la participación de estos sectores muy afectados por la política de atracción de inversiones a toda costa y una política de incentivos fiscales en un solo año (2014) hizo el Estado dejar de recaudar casi 2,5 mil millones de reales ${ }^{5}$. En la ausencia de estas redes, las decisiones se centralizaron en manos de los líderes políticos locales y estatales y a merced de los intereses de los grandes inversores que únicamente utilizan el territorio como medio para instalar empresas que hacen uso del territorio distinto del território para atender a los intereses del beneficio máximo y coste mínimo, sin estar comprometido con un proyecto local para el desarrollo territorial sostenible ni con el bienestar de los municipios y comunidades.

\section{ESCENARIOS Y ALTERNATIVAS PARA EL FUTURO}

Este tema tiene como objetivo reflexionar sobre las posibles intervenciones en el territorio de Suape con un escenario de múltiples desafíos que afectan a un productor territorio de la riqueza, pero poco incluyente y lleno de contradicciones, en la que viven algunos de los más altos PIB en el Estado de Pernambuco y grave violación de los procesos sociales y la degradación del medio ambiente, en gran parte el resultado de un modelo de desarrollo basado en la atracción de inversión extranjera.

\footnotetext{
${ }^{5}$ Confederação Nacional dos Municípios - CNM, 2014
} 
Ya es hora de utilizar la estratégia de solamente decir ventajas sobre este desarrollo, y impedir la discusión crítica del modelo adoptado por la imposición de este modelo por la fuerza, como la única opción. Es inaceptable para hacer la vista gorda a la gran devastación ambiental causada por la tala de los bosques, el entierro de los manglares - necesaria para mantener la vida de muchas especies - y la contaminación de los ríos y arroyos, que permitían el mantenimiento de la vida de toda la población con el fin. Además de los trágicos problemas sociales inducidos por una estrategia que debe ser revisada. (COSTA, 2014 e)

\subsection{La consciência de la crisis}

Para Nogueira (2009), un proceso de reflexión y planificación estratégica de un territorio para el desarrollo a nivel local y en vista de "abajo arriba" requiere "la existencia de un" caldo de cultivo "previo para asegurar una mayor posibilidad de éxito. Este "caldo de cultivo" sería una mezcla de dos elementos: conciencia de la crisis y el compromiso colectivo en torno a un proyecto de futuro para el territorio. El concepto de conciencia de la crisis "se refiere a la existencia de una cultura de mejora en un grupo suficientemente grande de la población de un territorio, lo que les hace pensar que la situación se encuentra en el territorio puede mejorar a través de la acción colectiva." La conciencia de la crisis es el elemento que desencadena el proceso. Sin la percepción de la existencia de un problema o la posibilidad de alcanzar una situación mejor que la actual, corre el riesgo de no iniciar el proceso correctamente. (NOGUERA, 2009 a).

También es importante tener en cuenta que la toma conciencia de esta crisis, no debe confundirse, dice Noguera, con una alarma social generalizada. Conciencia de la crisis no significa una situación catastrófica, o incluso si se refiere necesariamente a cuestiones negativas. Simplemente puede representar la percepción de que algo se puede mejorar y está directamente relacionada con la existencia de una cultura de mejora continua en la población. En esta primera etapa no se espera que la conciencia de toda la población del territorio, sino la creación de una minoría crítica involucrando funcionarios o actores clave en la sociedad local, y que sean conscientes de la situación del territorio con una percepción compartida de los problemas y las cuestiones que necesiten solución. Noguera (2009 b) sugiere tres preguntas claves que ayudarán a guiar la conciencia de los problemas y si es que existen:

- ¿Lo que funciona mal o necesita ser modificado?

- ¿Cuáles son los aspectos clave del problema?

- ¿Dónde está el problema y cuál es su naturaleza espacial o geográfica?

Esta etapa, parece ser, en la fase actual de evolución espontánea del desarrollo del territorio estratégico de Suape, el gran reto de Pernambuco, y sobre todo el liderazgo político del Estado y de los municipios de TES. No es tarea sencilla, en Pernambuco mirar críticamente en Suape. Todo imaginario construido por años de patrioterismo político y editorial que trató Suape como la oportunidad de redención del estado Pernambuco hizo con que la percepción común associe siempre a Suape la idea de la prosperidad y el crecimiento y nunca la crisis. Incluso hoy en día, a pesar de todas las consecuencias del proceso desordenado de ocupación del territorio sean palpables, pero sobre todo el 
gobierno del estado, se resiste a realizar una evaluación más crítica del proceso que pudiese crear esta conciencia de que debemos y podemos mejorar.

\subsection{Directrices para un nuevo acuerdo}

Tener conciencia de la crisis, no es conseguir el apoyo y compromiso suficiente de la sociedad y las instituciones locales. Antes, es esencial repensar la gobernanza del territorio. Se trata de la segunda fase del plan delineado por Noguera (2009c), que se centra en la creación de estructuras que pueden responsabilizarse por su gestión, y cuyas funciones se distribuyen en un órgano de coordinación para el plan, por lo tanto, debe incluir todas las partes interesados.

En este punto, el Gobierno del Estado de Pernambuco tiene que someterse a un reflejo más importante, que es acerca de su papel en esta revisión. Hasta la fecha, el gobierno del estado ha sido el centro de las decisiones. Esta centralización ha borrado a todos los demás actores afectados por el fenómeno de Suape, así como otros organismos técnicos y políticos que podrían hacer importantes contribuciones a la construcción de un modelo de desarrollo más sostenible, inclusivo y bases locales. Tal vez tan difícil como la toma de decisión la consciência de la crisis en el que debe pasar el territorio, es darse cuenta de la cuestión de la gestión centralizada como uno de los factores causales de la crisis misma. Y por mucho que esta autocrítica pueda ser difícil, en contra al optimismo y la imagen de gestión que proyecta, construída en los últimos años, es imprescindible para que el gobierno lidere el cambio.

Lo que se propone no es una reducción de la importancia del gobierno del estado, sino un cambio de papel, dejando la posición de quien toma todas las decisiones para un liderazgo que organiza, estimula y califica el proceso de toma de decisiones en el territorio a través de la inclusión de todos los actores, que salen de la sombra a la luz de la participación efectiva. Para que esto sea efectivo, es necesario crear una nueva práctica de la gestión de la red, retomando las experiencias como la de Suape el Foro Regional Estratégico establecido por la Agencia CONDEPE Fidem, la agencia del gobierno estatal, descritos en nuestra tesis, de esta vez profundizando y haciéndola más completa en términos de participación de la sociedad civil y las instituciones que representan el territorio y el Estado.

La experiencia de integración entre los municipios y las agencias estatales de aquel Foro resultó ser muy rico, y puede traer referencias importantes para la estructuración de una nueva red, en torno a un nuevo territorio permanente (Foro General de Suape) para, a partir de las perspectivas creadas por conciencia de la crisis, construir pautas para un nuevo pacto del territorio, con la participación de todos los interesados de una manera eficaz.

Tras la tarea urgente, y quizás la más importante de los nuevos instrumentos del gobierno, con el fin de revisar el modelo de desarrollo actual y de un territorio que fue llamado 'estratégico', dada su importancia para el futuro de Pernambuco, respondería a la siguiente pregunta: ¿estratégico para qué y para quién?

La respuesta a esta pregunta implica una discusión amplia y profunda sobre el desarrollo que se quiere para el territorio y para Pernambuco, teniendo en cuenta toda la 
multidimensionalidad del desarrollo, y que las políticas y las estrategias que deben adoptarse para que nadie, ninguna comunidad o grupo humano, esto o las generaciones futuras, ser excluido de los logros que el crecimiento económico puede proporcionar.

Es esencial discutir donde llegamos al actual modelo de desarrollo del Territorio de Suape y del propio Complejo Industrial y del Puerto, y definir los ajustes necesarios para equilibrar las distintas dimensiones del desarrollo, trayendo para el centro de los debates la necesidad de equilibrar el crecimiento y la preservación de los recursos naturales finitos y limitados. Pike, et al. (2011d) señala que el debate tiene que cuidar el equilibrio entre la eficiencia económica, los derechos sociales y la cohesión territorial, tratando de analizar quién pierde y quién gana la dinámica actual del territorio y cuáles son las zonas desfavorecidas y zonas desfavorecidas. (PIKE, et al., $2011 \mathrm{e}$ ).

Por un lado, el Territorio Estratégico necesita Suape, en igual medida, Suape necesita un territorio que funcione, bien planeado y gobernado en todos los aspectos, desde sus elementos naturales, como en los aspectos culturales, históricos y humano de modo amplio, y con el objetivo primordial, la calidad de vida de sus habitantes. La compensación, sin embargo, puede no ser la única regla, como se fuera un premio de consolación para el Territorio. La relación debe ser de integración, de modo que el territorio pueda ganar de la riqueza producida por el complejo y el complejo ganar por estar en un territorio que puede producir ambientales, bienes culturales, los servicios y la calidad de vida. (MASTER ECO-POLIS, 2009 a)

PIKE, et al., (2011 f), citando el Gobierno Comisión Local en 2004 en la publicación, señala acertadamente que uno de los mitos más difundidos es que para fomentar el desarrollo, una comunidad debe aceptar el crecimiento. La verdad sigue diciendo, es que es necesario diferenciar el crecimiento y el desarrollo: el crecimiento significa hacerte más grande, desarrollo significa hacer mejor a ti mismo - un aumento de la calidad y la diversidad. Usted puede imaginar, entonces, que en ciertos contextos, la respuesta a la pregunta: ¿estratégica para lo que, incluso puede incluir la decisión de limitar el crecimiento a favor de la promoción del desarrollo.

Otra cita destacada por PIKE, et al., (2011 g), destaca extracto del artículo "Descripción y lecciones aprendidas sobre el Desarrollo Económico Local, Desarrollo Humano y Trabajo Decente" de G. Canzanelli (2001), aporta una reflexión muy pertinente sobre la cuestión "¿estratégica para quién? ":

El desarrolo económico no es um objetivo de pôr sí. Es um medio para lograr el bienestar, según la cultura y las condiciones de cada población. No obstante, el objetivo de bienestar no es igual para las personas que viven em Nueva York o en Maputo. Sólo los habitantes de Nueva York o Maputo podrían definir lo que quieren lograr em el medio y largo plazo." (PIKE, et al., 2011 apud CANZANELLI, 2001, p. 65,66)

El enfoque de estas declaraciones a Suape, parece bastante obvio. Sólo el Territorio Estratégico de Suape, con todos sus actores y partiendo de una perspectiva "de arriba abajo" se puede definir, establecer y elegir la misión, los objetivos y los límites de su propio proyecto de desarrollo local. Porque, parafraseando al autor, sólo los habitantes 
del Territorio Suape Estratégico pueden definir lo que, para ellos, significa "bienestar", y por lo tanto lo que quieren lograr y dónde quieren llegar a medio y largo plazo.

\section{BIBLIOGRAFIA}

ADDIPER, 2014. PANORAMA PERNAMBUCO, RECIFE: INFORMATIVO TRIMESTRAL . Agência de Desenvolvimento Econômico de Pernambuco - AD Diper. № 3, Ano 1, Dezembro, 2014 http://www.sdec.pe.gov.br/wp-content/uploads/2014/12/PanoramaPE 3preview6.pdf

BARQUERO, A. V., 2006. Endougenus development: analytical and policy issues. The Regional Question in Economic Development. New York and London: Routledge.

BOISIER, S., 2001. Desarrollo (Local): ¿ De Qué Estamos Hablando ?. Editorial Homo Sapiens, Rosario, 2001p. 22.

BRAGA, M. d. C. d. A. \& QUEIROZ, A. S. d., 2009. Território Estratégico de Suape: diretrizes para uma ocupação sustentável. Humanae, Dezembro, I(3), pp. 54-65.

CONDEPE FIDEM, 2013. Ranking do IDHM, por municípios - Pernambuco - 2010. [Online] Available at: http://www.condepefidem.pe.gov.br/web/condepe-fidem/indice-dedesenvolvimento-humano-municipal-idhm

CONFEDERAÇÃO NACIONAL DOS MUNICÍPIOS - CNM, 2014. Estados e prefeituras vão ter perda bilionária de $\mathrm{R} \$ 66$ bilhões com a guerra fiscal, s.I.: s.n. http://www.em.com.br/app/noticia/politica/2014/02/14/interna politica,498225/esta dos-e-prefeituras-vao-ter-perda-bilionaria-de-r-66-bilhoes-com-a-guerra-fiscal.shtml

COSTA, H. S., 2014. Complexo De Suape: 36 Anos De Uma Triste História. Fórum Suape Espaço ambiental. [Online] http://forumsuape.ning.com/profiles/blogs/complexo-desuape-36-anos-de-uma-triste-historia

G1 - PERNAMBUCO, 2013. Falta de estrutura afasta turistas da praia de Gaibu, litoral sul de PE, Recife: s.n. http://g1.globo.com/pernambuco/noticia/2013/12/falta-deestrutura-afasta-turistas-da-praia-de-gaibu-litoral-sul-de-pe.html

GODOY, J. H. A. d., 2014. Novo desenvolvimentismo do Nordeste: industrialização, crescimento econômico e equidade no Território Estratégico de Suape. 38으 Encontro Anual da ANPOCS s.I., s.n., p. 35.

LIRA, I. S., 2005. Desarrollo económico local. REVISTA DE LA CEPAL 85, pp. 81-100. MASTER ECO-POLIS, 2009. SuapeGlobal / SuapeLocal. O Caminho Sinuoso do Desenvolvimento Integrado, Recife: Universita di Ferrara / Universita Della Calabria. http://www.masterecopolis.it/pages port/history/body/edition02/edit02 suape01.ht $\underline{\mathrm{ml}}$

MONITOR MERCANTIL, 2014. Ilegalidade da cobrança do Imposto de Fronteira para as microempresas, Rio de Janeiro: MONITOR EDITORA E GRÁFICA LTDA. http://www.monitormercantil.com.br/index.php?pagina=Noticias\&Noticia=155732\&Ca tegoria=TRIBUTOS\&CIA 
NOGUERA, J., 2009. Pensamiento y planificación estratégica. Definición e implementación de estrategias de desarrolo. Em: Gestión y promoción del desarrollo local. Valencia: Universitat de València, pp. 57-84.

PE DESENVOLVIMENTO., 2009.[Online]

Available at: http://pedesenvolvimento.com/2009/10/29/polo-naval-e-destaque-noplano-diretor/

PE_DESENVOLVIMENTO, 2010.[Online] Available at: http://pedesenvolvimento.com/2010/03/27/pernambuco-consolidacluster-naval/

PERNAMBUCO, S. D. D. E. -., 2014. [Online]

Available at: http://www.sdec.pe.gov.br/noticias/pe-fecha-2014-com-atracao-de-r139-bi-em-projetos-industriais/

PIKE, A., RODRIGUES-POSE, A. \& TOMANEY, J., 2011. Desarrollo local y regional. 2a ed. València: PUV - Universitat de Valencia.

PNUD, 2013. [Online]

Available at: http://www.atlasbrasil.org.br/2013/pt/

SEBRAE - NÚCLEO DE INTELIGÊNCIA TERRITORIAL - NIT, 2015 http://www.nit.sebrae.com.br/ 